\title{
BOCCACCIO EM MOVIMENTO: \\ IMAGENS E SEU PÚBLICO NO PALÁCIO SPANNOCCHI \\ (SIENA, 1494)*
}

\author{
Diogo Rodrigues de Barros \\ Mestre em História, École des Hautes Études \\ en Sciences Sociales
}

\section{Resumo}

Neste artigo, estudamos dois objetos produzidos na Toscana em 1494 para o duplo casamento dos irmãos Giulio e Antonio Spannocchi. Trata-se de uma série de painéis para spalliera, oferecidos como presente de casamento, e de uma peça teatral escrita para as festividades. Procuramos, por meio da análise desses objetos, compreender sua recepção pelos Spannocchi e por seus contemporâneos.

\section{Pallavras-chave}

Recepção • imagem • teatro.

Contato:

Avenida Clavásio Alves da Silva, 820, bloco 4, ap. 92.

CEP: 02722-030 - São Paulo -SP

E-mail:diogorbarros@yahoo.com

* Este artigo é uma versão condensada e reduzida da introdução e do segundo capítulo da minha dissertação de mestrado, intitulada Molte storie di figure piccole: la famille Spannocchi et la culture matérielle entre Sienne et Rome (1494-1513), defendida em setembro de 2009, na École des Hautes Études em Sciences Sociales (EHESS), sob a orientação de Jérôme Baschet.

** Todas as imagens mencionadas neste artigo estão reproduzidas no Caderno de imagens. 


\title{
BOCCACCIO IN MOVEMENT: IMAGES AND THEIR PUBLIC IN THE SPANNOCCHI PALACE \\ (SIENA, 1494)
}

Diogo Rodrigues de Barros

Master in History, École des Hautes Études en Sciences Sociales

\begin{abstract}
This article studies two objects produced in Tuscany, in 1494, for the double wedding of brothers Giulio and Antonio Spannocchi: a series of spalliera panels, offered as wedding gifts, and a play written for the celebrations. Through the analysis of these objects, we propose an approach to the study of their reception by the Spannocchi and their contemporaries.
\end{abstract}

\section{Keywords}

Reception $\bullet$ image $\bullet$ theatre.

\section{Contact:}

Avenida Clavásio Alves da Silva, 820, bloco 4, ap. 92.

CEP: 02722-030 - São Paulo -SP

E-mail:diogorbarros@yahoo.com 
Pierre Francastel afirma que "a imagem não é um duplo do real, mas uma etapa, algo intermediário. Ela não é idêntica ao objeto nem à rede de signos, ela está no campo do imaginário. E, para cada um de nós, a visão, ativa, alimentada por experiências e por lembranças nunca coincidentes, é um ato de confrontação entre os fatos atuais e os fatos da memória, isto é, entre a percepção e o conhecimento". ${ }^{1}$ Como alcançar esse imaginário de que fala Francastel? O próprio autor sugere um caminho: podemos atingir o imaginário por meio de um estudo que abarque tanto a percepção como o conhecimento daqueles que veem a imagem que nos interessa. É preciso, portanto, em primeiro lugar, estabelecer que o sentido de uma imagem não existe a não ser no momento do seu encontro com um espectador.

É nessa perspectiva que nos propomos a estudar aqui a recepção histórica de dois objetos produzidos para o duplo casamento da família Spannocchi, em Siena, em 1494. Em janeiro daquele ano, casaram-se, em festa conjunta e suntuosa, os irmãos Antonio e Giulio Spannocchi. Os Spannocchi eram uma importante família de banqueiros sieneses que se tornaram atores fundamentais de sua época, sobretudo por terem exercido por muito tempo o controle das finanças do papado. Para a celebração desses casamentos, foram encomendados diversos objetos, dentre os quais uma série de painéis da história da paciente Griselda, última novela do Decameron, ${ }^{2}$ e uma peça teatral, a Virginia, ${ }^{3}$ uma reelaboração de outra novela da mesma obra de Boccaccio. ${ }^{4}$

Não se pode, evidentemente, conhecer a percepção particular precisa que os Spannocchi tiveram dos painéis da história de Griselda ou da peça teatral Virginia quando das núpcias de 1494. O que nós tentaremos compreender, portanto, são as possibilidades de recepção desses objetos tendo em vista as convenções formais a partir das quais eles foram produzidos e compreendidos à época dos Spannocchi e de seus convidados.

Chamamos aqui de objetos tanto os painéis da história de Griselda como a Virginia, peça teatral de Bernardo Accolti. O que é um objeto nessa concepção? Um objeto é toda existência material percebida por homens graças a sua forma, a sua existência material, em pedra, em madeira, em ondas sonoras etc. A produção de um sentido a partir desses objetos faz-se no tempo e nas relações sociais; ela

1 FRANCASTEL, Pierre. La figure et le lieu: l'ordre visuel du Quattrocento. Paris: Gallimard, 1967 , p. 37 e 38.

2 BOCCACCIO, Giovanni. Decameron. Turim: Giulio Einaudi, 1980 (Edição de Vittore Branca), v. 2, p. 1232-1248.

3 ACCOLTI, Bernardo. La Virginia. Bolonha: Arnaldo Forni, 1983 [1519, edição anastática].

4 BOCCACCIO, Giovanni. Decameron, op. cit., v. 1, p. 429-442. 
é, portanto, necessariamente ligada a um evento. Esse objeto-evento não é uma constante, mas uma eterna dialética entre objeto e seus espectadores em meio às alterações do espaço e do tempo da percepção.

Estudando a recepção da Virginia e dos painéis da história de Griselda juntos buscaremos compreender quais eram os sentidos possíveis para esses objetos no interior do sistema de percepção no qual eles se inseriam. Tentaremos identificar os traços gerais desse sistema por meio do estudo de cada objeto e da busca de padrões na comparação entre eles. Procuraremos entender a maneira como o evento, isto é, o encontro entre espectador e objeto é condicionado por um sistema de percepção específico no tempo e no espaço.

\section{Os painéis da história de Griselda ${ }^{5}$}

A história da paciente Griselda, décima novela do décimo dia do Decameron, de Boccaccio, fala de uma camponesa que vive com sua família no território do marquês Gualtieri di Saluzzo. O marquês escolhe Griselda como esposa sob a condição de que ela lhe seja em tudo obediente. Após o casamento, ele começa a testá-la em sua promessa, privando-lhe, inicialmente, de seus filhos e dandolhe a entender que eles haviam sido mortos. Em seguida, Gualtieri a expulsa do palácio, afirmando que o papa consentira com a anulação do casamento. Anos mais tarde, o marquês ordena a volta de Griselda para que ela prepare a casa para uma festa em que o marquês voltaria a se casar. Griselda, sempre obediente e sem nenhum questionamento, prepara a casa para as festividades. Ao final, é revelado à protagonista que tudo não passara de um teste. Seus filhos estão vivos, a noiva com que o marquês supostamente se casaria é sua filha e Griselda pode ser finalmente aceita como esposa e verdadeira marquesa de Saluzzo.

A novela de Griselda fez grande sucesso por toda a Europa e diversas foram as suas versões até ao menos o século XVIII. A história de suas "reescritas" começa já à época de Boccaccio com uma versão latina da narrativa, ela mesma célebre, escrita por Petrarca e inserida nas Res Seniles. ${ }^{6}$ Em uma carta a Boccaccio, que precede a tradução/versão de Petrarca, este expõe seu objetivo: tornar conhecida a um público mais amplo no exterior - versado em latim, mas não necessariamente em italiano - a história de Griselda. A essa versão contemporânea, sucederam-se muitas outras, tanto na Itália como em outros países da Europa. ${ }^{7}$

5 Imagens de alta qualidade e com mecanismo de zoom podem ser encontradas online no site da National Gallery de Londres.

6 PETRARCA, Francesco. Res Seniles. Florença: Le Lettere, 2009, XVII, 3.

7 Para as várias versões da história de Griselda no Quattrocento e para uma transcrição da versão 
Dentre as versões, poderíamos mencionar a de Jacopo Foresti, publicada no $\mathrm{Su}$ pplementum Chronicarum, edição de 1485, o que mostra o interesse despertado por essa narrativa à época do casamento dos irmãos Spannocchi. ${ }^{8}$ Essa obra seria traduzida do latim para o italiano já em 1491, testemunhando o intenso trânsito entre línguas vernaculares e o latim que ocorria nos círculos letrados italianos naquele momento.

A série de painéis com esse tema, que hoje pertence à National Gallery de Londres, foi produzida por um único mestre anônimo, conhecido precisamente como mestre da história de Griselda, para decorar o quarto de um dos casais das bodas de 1494, no palácio Spannocchi. A literatura que busca identificar esse anônimo é bastante extensa e considera-se, em geral, surpreendente que, dada a qualidade do trabalho e a importância da encomenda, não existam informações precisas sobre ele. Assim sendo, a maior parte dos trabalhos busca identificá-lo como uma fase de juventude de um pintor mais conhecido. ${ }^{9}$

A própria origem da encomenda da série da paciente Griselda foi um tema de amplo debate. A sugestão de Vilmos Tátrai, em um artigo de 1979, de atribuir os painéis a uma encomenda para o duplo casamento Spannocchi de 1494 não foi inicialmente aceita, sendo que a maior parte dos especialistas acreditava numa provável encomenda de membros da família Piccolomini. ${ }^{10}$ Pesquisas recentes parecem, no entanto, confirmar as conclusões de Tátrai. Esse é o caso de um estudo publicado recentemente no National Gallery Technical Bulletin, volume 27, que confirma a conexão dos painéis aos Spannocchi por meio de comparação com um painel de Alexandre, o Grande, hoje no Victoria and Albert Museum. ${ }^{11}$ Nos dois casos, veem-se serviçais vestidos com calças com as cores dos Spannocchi em uma perna e dos Piccolomini em outra. Ambrigio Spannocchi, pai dos noivos, antigo banqueiro do papa Pio II, Piccolomini, recebera o direito de incorporar as cores e o brasão dessa família a suas próprias cores e a seu brasão. Essa conexão plástica da série da Griselda com um painel mais seguramente

latina de de Jacopo Foresti, ver MORABITO, Raffaele. Una sacra rappresentazione profana: fortune di Griselda nel Quattrocento italiano. Tübingen: Max Niemeyer Verlag, 1993 (Beheifte zur Zeitschrift für romanische Philologie).

8 FORESTI, Jacopo. Supplementum chronicarum. Brescia: Boninus de Boninis de Ragusia, 1485.

9 Para uma lista de diversas tentativas de identificação desse mestre, ver DUNKERTON, Jill, CHRISTENSEN, Carol e SYSON, Luke. The master of the story of Griselda and paintings for Sienese palaces. The National Gallery Technical Bulletin: Renaissance Siena and Perugia 14901510, 27, 2006, p. 62, nota 5.

${ }^{10}$ TÁTRAI, Vilmos. Il maestro della storia di Griselda e una famiglia senese di mecenati dimenticata. Acta Historiae Artium Academiae Scientiarum Hungaricae, 25, 1979, p. 27-66.

${ }^{11}$ DUNKERTON, Jill, CHRISTENSEN, Carol e SYSON, Luke. The master..., op. cit. 
atribuído aos Spannocchi, somada a outros levantamentos de Tátrai, confirma, então, a encomenda por parte dessa família.

A série da paciente Griselda é composta de painéis para spalliera, isto é, painéis historiados situados à altura dos olhos ou dos ombros, seu nome sendo derivado do termo italiano spalla, em português, ombro. ${ }^{12}$ Esse nome indica menos o tipo de objeto de que se trata do que o local a que ele se destinava, o que é confirmado pelo emprego do mesmo termo para tecidos, tapeçarias e decorações de armários que, nos palácios toscanos do Quattrocento, eram presos à parede à mesma altura.

As pinturas para spalliera decoravam as paredes de antecâmaras ou de quartos de dormir. Esses painéis eram frequentes na Toscana, especialmente em Florença e em Siena, entre 1470 e 1520. Cada painel ou série de painéis podia aparecer isoladamente sobre a parede ou acima de um lettucio (espécie de leito) ou cassone (baú também ligado à celebração de casamentos), sempre integrados à arquitetura, emoldurados por estruturas de madeira. Sobre a instalação desses painéis nas casas do Renascimento, a quantidade de testemunhos é, infelizmente, bastante reduzida. Entre os documentos mais interessantes está a obra Le vite, de Giorgio Vasari, em que o autor menciona alguns painéis que ele pudera ver in loco, ainda que eles fossem já a essa época considerados como fora de estilo. ${ }^{13}$

A encomenda desses painéis fazia parte das preparações tradicionais feitas para os casamentos toscanos à época. Enquanto à família da noiva cabia oferecer o dote, a família do noivo deveria oferecer à noiva uma série de presentes, dentre os quais, jóias, roupas e móveis para o quarto do casal. Esse contexto de produção dos painéis era determinante para a escolha das narrativas. Escolhiam-se sempre histórias ditas edificantes ou moralizantes, que deveriam servir como modelos de virtude aos noivos por meio de mensagens de amor, lealdade e tradição familiar. Essa suposta função das imagens aparece em tratados de moral que versavam sobre o bom funcionamento da família. Desses tratados, sabemos, portanto, que

${ }^{12} \mathrm{O}$ único estudo dedicado exclusivamente às pinturas para spalliera como gênero específico na pintura italiana do Renascimento é BARRIAULT, Anne B.. Spalliera paintings of Renaissance Tuscany: fables of poets for patrician homes. Pensilvânia: University Park, 1994. Outros estudos que abordam o tema são: CANTELLI, Giuseppe. La vita sociale e la nuova dimensione dell'abitare. In: RESTUCCI, Amerigo (org.). L'architettura civile in Toscana: il Rinascimento. Milão: Silvana, 1997, p. 300-329. MOTTURE, Petta e SYSON, Luke. Art in the casa. In: AJMARWOLLHEIM, Marta e DENNIS, Flora (org.). At home in Renaissance Italy. Londres: V \& A Publications, 2006, p. 268-283.

${ }^{13}$ VASARI, Giorgio. Le vite (edizioni giuntina e torrentiniana). Edição eletrônica de Signum (Centro di ricerche informatiche per le discipline umanistiche) e Scuola Normale Superiore di Pisa, 1999: http://biblio.cribecu.sns.it/vasari/consultazione/Vasari/indice.html 
a educação moral dos espectadores era a função declarada desses painéis. Parecenos, no entanto, que é preciso estar atento ao perigo de colar-se excessivamente ao discurso contemporâneo, posto que ele é apenas um dos componentes da experiência de interação com as imagens, sendo que as condições de visualização, a forma plástica e outros elementos não devem ser negligenciados. ${ }^{14}$

Otto Pächt acusou Ernest Gombrich de reduzir as pinturas a mensagens. Segundo ele, nos trabalhos de Gombrich, "a arte é um procedimento de embalagem, que consiste em transportar certas informações que teriam, não fosse isso, evidentemente, dificuldade de alcançar seus destinatários - informações que estes devem retirar de seus envelopes". ${ }^{15}$ Parece-nos que reduzir a função das pinturas para spalliera - ou sua recepção - à transmissão de mensagens moralizantes sem levar em conta a especificidade da linguagem pictórica seria cometer esse mesmo erro.

Buscando definir as pinturas para spalliera como gênero pictural, Anne Barriault levanta alguns elementos formais que seriam comuns a todas as pinturas do gênero: 1) tamanho característico; 2) escala e número de figuras; 3) construção do espaço em cada imagem; 4) escolha da continuidade dos enquadramentos para criar uma experiência visual de circundamento; 5) motivos com cores entrelaçadas; 6) temas e os modos narrativos constantes. A intenção da autora é, sobretudo, criar uma diferenciação clara entre os painéis para spalliera e aqueles para cassone, mais conhecidos pelos historiadores da arte. ${ }^{16}$

Os painéis para spalliera são maiores que os de cassone; suas figuras, sempre de tamanho reduzido, não são muito numerosas e se distribuem em um espaço regulado pela perspectiva albertiana; as figuras ocupam dois quintos da altura e são bem integradas ao enquadramento da pintura; o tamanho das figuras diminui de um plano a outro por meio de uma organização matemática do espaço. A paisagem de cada uma das imagens é sempre contínua, sendo que todas as cenas de uma mesma narrativa são dispostas em um mesmo espaço unificado, sem cortes ou enquadramentos, um mesmo personagem podendo aparecer diversas vezes ao longo desse espaço em momentos diferentes da narrativa. Esse tipo de organização narrativa no espaço chama-se "narração contínua" ou "narração

\footnotetext{
${ }^{14}$ Anne Bariault, por exemplo, analisa a dimensão plástica geral das pinturas para spalliera, na segunda parte de seu livro, e faz uma análise dos temas dos painéis que é completamente centrada na ideia de moralização, na terceira parte. Em nenhum momento, a autora considera a materialidade das imagens como elemento importante para a sua recepção. BARRIAULT, Anne B.. Spalliera paintings of Renaissance Tuscany, op. cit.

${ }^{15}$ PÄCHT, Otto. Questions de méthode en histoire de l'art. Paris: Macula, 2000, p. 77.

${ }^{16}$ BARRIAULT, Anne B.. Spalliera paintings of Renaissance Tuscany, op. cit., p. 56-94.
} 
de espaço contínuo" e foi muito popular no Quattrocento. No que diz respeito às relações entre espaço e tempo da narrativa, é preciso atentar também para a distinção entre narrativa linear e não-linear. Alguns painéis para spalliera apresentam um ordenamento claro das cenas da esquerda para a direita, enquanto outros dispõem as cenas ao longo do espaço sem ordem aparente, cabendo aos espectadores estabelecer a ordem de visualização de cada uma.

Vistas as características gerais do gênero, passemos às características específicas da série da história de Griselda [fig. 1, fig. 2, fig. 3, págs. 266 e 267]. Os três painéis possuem, cada um, características bastante particulares do ponto de vista formal. Isso não quer dizer, no entanto, que inexista unidade no conjunto. A arquitetura clássica - arcos e arcadas - é onipresente na série, sendo que o espaço ocupado pelas estruturas arquitetônicas aumenta progressivamente de um painel para o outro, passando de um plano mais recuado a planos cada vez mais próximos. Essa progressão conclui-se no último painel, em que a grande loggia sob a qual ocorre o banquete das núpcias ocupa toda sua extensão. Esse avanço da arquitetura em direção ao primeiro plano é um dos elementos mais importantes para localizar no tempo a progressão da narrativa, o passado distante correspondendo à arquitetura recuada, e o passado próximo, a uma arquitetura dominante no espaço pictórico.

As arcadas não são os únicos elementos arquitetônicos presentes nos painéis. A casa dos pais de Griselda é também uma constância. A dinâmica de sua apresentação é, entretanto, inversa àquela das estruturas clássicas: a cada painel, a casa pobre da família de Griselda torna-se menor. Vale notar que a localização dessa casa nos três painéis mostra que não há um espaço plástico contínuo ou contíguo entre os três painéis da série, já que a localização da casa no espaço não segue nenhuma lógica geográfica em sua relação com as outras estruturas. Os únicos elementos que nos permitem ver tratar-se, de fato, da casa dos pais de Griselda são a constância cromática - sua cor salmonada característica - e o fato de não ser uma construção em estilo clássico, como todas as associadas ao marquês de Saluzzo.

Além dos elementos arquitetônicos, os painéis da série da paciente Griselda têm em comum o que nos parece ser um princípio central para a sua recepção, a instabilidade como elemento (des)ordenador. Nada na série, nem a relação entre os painéis nem a estrutura interna de cada um, permite descansar o olhar, isto é, não mais deslocá-lo. O princípio da instabilidade obriga a um movimento constante em busca de uma simetria ou de uma centralização que permita o repouso, o que não encontramos em momento nenhum. Um elemento fundamental desse fenômeno é o fato de que nenhuma dessas imagens apresenta figuras perfeitamente 
centralizadas, que possam servir de ponto de referência a partir do qual passar a outros elementos da composição. Há sempre um pequeno deslocamento, que torna toda centralização falsa: 1) no primeiro painel, a cena do casamento não está centralizada em relação à abertura do arco no plano mais recuado; 2) no segundo, Gualtieri, no "centro" da composição, projeta-se em direção a Griselda quando da anulação do casamento; 3) há uma coluna no centro do terceiro painel, enquanto as cenas importantes se passam à direita e à esquerda.

Nos painéis 2 e 3, nos quais as cenas mais importantes ocorrem no interior das estruturas arquitetônicas, há sempre personagens que atravessam essas estruturas - seja com o olhar, seja com o corpo - o que evita a criação de enquadramentos materiais para as cenas. Sob o mesmo princípio da instabilidade, consegue-se, ao mesmo tempo, manter a unidade do espaço pictórico no interior do painel e, uma vez mais, estimular o movimento do olhar do espectador.

Do movimento do olhar, passamos aos movimentos dos personagens. Esses dois movimentos, um do espectador e o outro um movimento plástico, são necessariamente conectados um ao outro: é porque o olhar apreende a passagem de uma cena a outra que os personagens se deslocam nos painéis. Isso porque é o olhar que deve isolar as diferentes cenas no tempo, tornando, dentro da narrativa de espaço contínuo, certa imagem de Griselda, por exemplo, única.

Não poderíamos, no entanto, atribuir o movimento das personagens unicamente ao movimento do olhar dos espectadores. O movimento dos personagens se dá também por mecanismos plásticos. A tensão presente nos corpos das figuras humanas e mesmo dos animais será, por exemplo, fundamental para instaurar uma necessidade de movimento. Nos painéis de que tratamos, a torção dos corpos é sempre bastante intensa. Essa deformação força a antecipar o movimento lógico que parece estar em curso. À esquerda da figura nua da Griselda, por exemplo, um homem coloca seu braço sobre os ombros de outro de uma maneira muito pouco usual. Sua cabeça está virada para a esquerda em uma forte torção. A Griselda nua, ao lado, produz uma impressão bastante diferente, posto que ela tenta, pudicamente, reduzir a extensão de seu corpo. Tudo ao redor dela se move, ao passo que ela está imóvel. Pernas bastante tensionadas produzem esse mesmo efeito de movimento em curso, tensão de movimento. Vemos isso, por exemplo, observando os cavalos, Gualtieri na cena da Griselda nua, e os empregados de Gualtieri ao lado do poço, todos exemplos do primeiro painel. Os movimentos do olhar e os movimentos sugeridos pelas torções colocam dialeticamente, portanto, a composição em movimento. Essas tensões de movimentos têm estreita relação com a organização da narrativa, pois nos ajudam a visualizar a narrativa em movimento e, consequentemente, a passagem do tempo. A composição conta 
com o espectador para completar o movimento indicado pelas formas plásticas, ao mesmo tempo em que depende de movimentos de seu olhar.

Ainda no tocante à relação entre painéis e espectadores, parece-nos importante observar a presença de múltiplas formas de existência de figuras animadas. Vemos animais e pessoas que participam da história de Griselda, animais e figuras humanas esculpidos e figuras em relevo sobre a arquitetura. Esse jogo de iconografia no interior da iconografia poderia muito bem estender-se para os espectadores, que se tornam assim outro nível de existência nesse conjunto proposto pelos painéis. Os espectadores não são externos aos painéis, posto que são um dos elementos de uma cadeia de existências que integra o interior da composição ao espaço real de onde são vistas as imagens.

Vistos alguns aspectos gerais da série da paciente Griselda, detemo-nos agora brevemente sobre cada um dos painéis. Dado o espaço reduzido de que dispomos, ressaltaremos, em cada painel, alguns dos seus mecanismos plásticos mais específicos, ainda que vários desses mecanismos se repitam em mais de um ou nos três. No primeiro painel [fig. 4, pág. 267], os espaços dos grupos humanos, situados na metade inferior da imagem, são sempre circulares. Esses círculos, assim como aquele formado pelo arco de triunfo do centro da composição, produzem um efeito de eco que é fundamental para a articulação visual da composição e, consequentemente, essencial para conduzir o olhar dos espectadores. A formação de círculos é feita a partir das formas, sobretudo aquelas produzidas pelo posicionamento dos corpos, combinadas a uma disposição estratégica das cores. Identificamos, da esquerda para a direita, três "grupos circulares" principais:

1) Circulo formado por Griselda, Gualtieri, seus servidores e os cavalos. As formas circulares se constroem graças a uma oposição fundamental entre, de um lado, o marquês, dois servidores a sua esquerda e os cavalos, que se inclinam para a direita; e, do outro, Griselda e o servidor imediatamente a sua esquerda, os dois inclinados para a esquerda.

2) Griselda e Gualtieri na cena da troca dos anéis, no centro do painel. As cabeças dos noivos, inclinadas uma em direção à outra, formam um círculo reforçado pela repetição das cores vermelha e dourada.

3) A Griselda nua e Gualtieri a sua direita. O círculo se forma quando um se inclina em direção ao outro, fechando-se embaixo pela posição das pernas dos dois. 
À instabilidade do conjunto, produzida pelo efeito de eco das formas circulares, contrapõem-se, no entanto, elementos de ordenamento. A disposição das cenas principais cria uma diagonal, da esquerda para a direita, da metade superior para a inferior. Essa tensão entre a progressão para a direita e sua interrupção pelos movimentos internos a cada grupo parece-nos ditar o funcionamento elementar de condução do olhar dos espectadores. A narrativa disposta ao longo do painel exige um deslocamento continuo do olhar, e o que impede os espectadores de repousar o olhar sobre certas figuras ou sobre um grupo específico são precisamente as formas circulares, as passagens entre os grupos e a "centralização não-centralizada" do casal na troca de anéis.

Essas oposições entre movimento ordenado e instabilidade são também organizadoras do tempo no interior da imagem. O movimento interno aos grupos circulares produz o tempo de cada cena, o tempo dos diálogos, das trocas entre as diferentes personagens no interior do grupo-evento, enquanto as passagens de um grupo a outro e a progressão da esquerda para a direita criam a progressão da narrativa, isto é, a conexão entre os diferentes eventos, a passagem de uma cena à outra da narrativa. Os movimentos promovidos pelas formas circulares não permitem, insistimos, repousar o olhar sobre uma figura isolada, mas antes favorecem um movimento contínuo de idas e vindas que, na ausência do movimento oposto de passagem ao grupo seguinte imediatamente à direita, tenderia ao infinito, a um continuum.

Algumas figuras "secundárias" têm um papel importante no esquema de condução do olhar dos espectadores. Trata-se de figuras que chamaremos de "figuras de transição narrativa", cuja função é enquadrar as cenas principais, criando, ao mesmo tempo, uma transição entre elas. Há dois tipos de figuras de transição narrativa, aquelas que nos observam diretamente e aquelas que estão de costas para nós. As figuras de costas mimetizam a posição dos espectadores diante do painel, espectadores que, convertidos em personagens por meio dessa identificação, "conversam" com a figura colocada de frente e adentram, dessa maneira, o espaço pictórico.

Esse mecanismo é especialmente claro no segundo painel da série, em que os pares de figuras de frente e de costas em primeiro plano são essenciais para posicionar os espectadores diante dos - ou nos - painéis. As figuras de costas assumem claramente uma posição que é a mesma dos espectadores que observam o interior da imagem. Eles são, portanto, nosso ponto de acesso ao espaço pictórico, uma projeção dos espectadores que se tornam eles mesmos parte daquilo que observam. O ponto de vista dos espectadores não é, portanto, livre, sendo evidentemente condicionado por essas figuras que são nossa existência 
na pintura. Um exemplo dessa predeterminação é o fato de que as figuras olham para a direita, o que reforça o direcionamento do olhar nessa direção, guiando assim uma vez mais o nosso olhar.

Nossos alteregos não estão sós, no entanto, pois formam pares com figuras de frente, às quais se sobrepõem parcialmente. Esses encontros, que nos dão a impressão de duas pessoas que conversam - talvez sobre as cenas que ocorrem atrás deles, nos planos mais recuados - reforçam nossa adesão à imagem, uma vez que, identificados às figuras que imitam nossa posição diante da pintura, nós também acompanhamos as cenas e conversamos sobre aquilo que observamos.

Na série de Griselda, este segundo painel é aquele em que a perspectiva é mais cuidadosamente construída, como comprovam as linhas do desenho de base visíveis sob a pintura [fig. 5, pág. 268]. Além disso, o fato de que as figuras sob a loggia estejam de pé sob uma estrutura cuja profundidade é bem definida permite a disposição das figuras humanas de modo que umas se sobreponham às outras de maneira bastante lógica para as regras de perspectiva. Esse efeito é reforçado pela presença de planos mais recuados à esquerda e à direita, o que inclui uma passagem narrativa, o(s) bebê(s) retirado(s) de sua mãe, à esquerda. No mesmo sentido, deve-se notar a presença de personagens no primeiro plano, próximos ao limite da imagem, ao enquadramento, e a figura de Griselda, que avança em direção ao canto inferior direito, alargando assim o espaço para além da pintura em si.

Quanto à direção da narrativa, como no primeiro painel, há um movimento diagonal da esquerda para a direita e de cima para baixo. Este movimento é criado em razão de: 1) uma sequência de figuras douradas, composta sobretudo por uma sequência de Gualtieris e Griseldas. As cores são um recurso frequentemente empregado no conjunto dos painéis para conectar as diferentes partes de cada painel, estabelecendo um caminho a ser seguido pelo espectador tal como vemos no esquema a seguir: 2) O desenvolvimento das cenas de um plano recuado à esquerda - retirada dos bebês - em direção a um plano mais próximo - a partida de Griselda após a anulação do casamento - na extrema esquerda da composição. Esse deslocamento segue a ordem cronológica da narrativa, de maneira que as cenas que estão mais distantes no tempo correspondam àquelas que estão mais distantes no espaço. O tempo da narrativa neste painel torna-se, portanto, o próprio tempo do deslocamento do olhar do espectador do plano recuado da esquerda para o plano próximo da direita.

O movimento da esquerda para a direita não é, no entanto, o único a orientar o olhar do público. Há elementos importantes de contenção - ou de dinamização - desse movimento, principalmente os olhares dos convivas para as mais diversas direções e a presença de colunas, que isolam algumas cenas da narra- 
tiva, impondo assim cortes à progressão. Também em oposição ao movimento dominante da esquerda para a direita, podemos notar outra linha cromática, que cria um movimento constante frente-trás e é composta por várias figuras vestidas inteiramente ou parcialmente de vermelho [figura 6, pág. 268]:

Do ponto de vista formal, o terceiro painel é marcadamente diferente dos outros dois. A ausência de cenas narrativas centrais e uma ocupação importante da metade superior da composição, dominada pela grande loggia, altera substancialmente a disposição das figuras nesse painel. Além da arquitetura, é preciso ressaltar a presença importante do cortejo sobre a linha do horizonte, com seus estandartes e as árvores que avançam para o limite superior da pintura, preenchendo o espaço do céu acima dos convivas sentados sob a loggia. Por causa do número reduzido de planos e da perspectiva pouco expressiva, a ocupação das metades superior e inferior do painel é bastante homogênea. Abaixo, pode-se notar que o espaço livre diante da construção arquitetônica é bem mais estreito que nos outros painéis. Por fim, as colunas dividem a imagem em várias partes como em um retábulo, mas, como nos retábulos da mesma época, a imagem ultrapassa os limites arquiteturais. Ultrapassam os limites dos enquadramentos: o cortejo da noiva (na realidade a filha de Gualtieri e Griselda), a mesa do banquete, e os olhares dos serviçais em pé sob a loggia.

Quanto à direção do olhar dos espectadores sobre esse painel, um primeiro elemento que deve ser levado em consideração é a posição das figuras humanas (de frente e de costas), que nos remetem sem cessar a diferentes pontos do painel. Em uma imagem em que as colunas são numerosas e em que nenhuma cena narrativa é central, essas figuras funcionam como pontos de referência. Entre elas, os dois primeiros serviçais da esquerda para a direita estão no mesmo plano e, olhando o primeiro para a direita e o segundo para a esquerda, remetem ao beijo entre Gualtieri e Griselda. As duas figuras funcionam, assim, como enquadramento desta cena. $\mathrm{O}$ terceiro serviçal, de costas, olha em diagonal para a direita e nos conduz ao encontro de Griselda com sua filha, enquanto o quarto, em posição inversa - de frente, olhando para a esquerda -, reconduz ao centro da imagem. O mesmo papel é desempenhado pela conviva vestida de escarlate, que está em pé no primeiro plano à esquerda.

As figuras de pé têm, portanto, a função de dizer aos espectadores a direção para a qual devem olhar, indicando quais são os elementos fundamentais da narrativa. Posto que não há ordem narrativa - a narrativa é não-linear - o papel formal das figuras de pé é também fundamental para o estabelecimento de uma sequência de cenas: é no movimento constante de um lado a outro da imagem que os espectadores, orientados pelos olhares das diferentes figuras, conseguirão fazer 
o percurso narrativo desejado. Para isso, é necessário considerar-se também que os espectadores conhecem a história contada e buscarão, portanto, reconstituir sua sequência lógica conhecida. Trata-se de um verdadeiro jogo, uma vez que os direcionamentos não são ordenados e não impõem, pois, do ponto de vista formal, uma sequência narrativa predeterminada.

\section{Virginia, de Bernardo Accolti}

A Virginia, única peça escrita pelo poeta florentino Bernardo Accolti, é uma comédia em cinco atos, introduzida por um argumento e um proêmio, que conta a história da personagem-título, a qual, filha de um médico, consegue curar o rei de uma doença terrível e, como recompensa, pede para ter o príncipe de Salerno como marido. O príncipe, obrigado a tomá-la como esposa, vai embora logo após o casamento, abandonando-a e partindo para Milão para participar da guerra contra os franceses. Ele não retornará a não ser que Virginia consiga realizar algumas tarefas que ele julga impossíveis. Por meio de sua inteligência, no entanto, Virginia faz o que o príncipe lhe pede e é finalmente aceita como esposa. Essa história é uma versão da novela de Giletta di Narbona, do Decameron (nona novela do terceiro dia), sem que haja, no entanto, simples transposição da novela ao teatro.

Uma diferença fundamental em relação à história de Boccaccio são, por exemplo, as alterações geográficas feitas por Accolti: enquanto na novela de Giletta di Narbonna, Gilette e o príncipe são ambos franceses e, após o casamento, o príncipe parte a Florença para unir-se a essa cidade na guerra contra os sieneses, na versão de Accolti, os personagens são de Salerno, e o príncipe parte a Milão para participar, ao lado do duque dessa cidade, da batalha contra os franceses. O motivo dessa mudança não é de difícil compreensão: um príncipe que parte a Florença para se aliar a essa cidade contra os sieneses não seria visto com bons olhos pelos Spannocchi de Siena.

Uma edição moderna da Virginia foi preparada como tese de doutoramento na Universidade de Harvard por Adele Giada Calise, em 1984. ${ }^{17}$ A autora faz também uma introdução baseada em alguns testemunhos da época para traçar uma curta biografia de Accolti e apresenta parcialmente uma fortuna moderna da Virginia. A edição de Calise é baseada na edição florentina de 1513, que Calise,

${ }^{17}$ CALISE, Adele Giada. "La Virginia” di Bernardo Accolti (una comedia inedita del XV secolo): edizione critica. Tese de doutorado. Department of Romance Languages and Literatures, Harvard University, 1984. 
seguindo autores do século XIX, acredita ser a princeps - há, na verdade uma edição sienesa de 1512 - e no manuscrito Palatino 277 da Biblioteca Nazionale Centrale, em Florença, datado do final do século XV, mas que a autora crê ser posterior à edição de 1513 , a qual ela privilegia em sua transcrição. ${ }^{18}$

O único objetivo da edição de Calise é estabelecer o texto "original" da Virginia. Sua abordagem ignora completamente o hábito da época, isto é, a produção de cópias manuscritas destinadas a grandes senhores, enquanto as cópias impressas, frequentemente produzidas à revelia do autor, eram destinadas a um público mais amplo. ${ }^{19}$ Assim sendo, não é, portanto, a data que explica as variações formais, mas as particularidades da circulação e dos suportes. As variações linguísticas que Calise tenta identificar são, em nossa opinião, variações de ocasião de acordo com os destinatários do manuscrito ou com a cidade de impressão de cada edição. Essa abordagem cronológica em busca da "obra original" parece-nos anacrônica em uma época em que as relações entre autor, texto e público organizavam-se de maneira bastante diversa.

Os estudos sobre Bernardo Accolti e, especificamente, sobre a Virginia são bastante raros. O estudo mais detalhado é aquele de Elvira Guarnera, Bernardo Accolti: saggio biografico-critico, no qual, além da biografia do autor, encontra-se um estudo da Virginia. Trata-se, no entanto, de um trabalho de 1901 que, do ponto de vista teórico, é bastante datado. Guarnera deseja mostrar a "originalidade" da obra e a audácia de seu autor, que transpusera a forma das sacre rappresentazioni para o teatro profano, deixando de lado o que, segundo ela, eram personagens fossilizados pelo dogma, para criar personagens vivazes por meio dos quais se exprimiria a "personalidade do artista", em que ela identifica até mesmo o início do "elemento romântico do mundo de Shakespeare". ${ }^{20}$

Não existe nenhuma referência a como foi encenada essa peça durante as bodas Spannocchi de 1494, única montagem dessa obra de que se tem notícia. Não se conhecem, portanto, descrições de cenários, figurinos ou da movimentação dos personagens em cena. Que possibilidade temos, então, de estudar a recepção dessa

${ }^{18}$ Para amplo estudo das edições da Virginia, sua circulação e as lógicas sociais em que elas se inserem, ver BARROS, Diogo Rodrigues de. Molte storie di figure piccole: la famille Spannocchi et la culture matérielle entre Sienne et Rome (1494-1513). Disseração de mestrado. École des Hautes Études em Sciences Sociales, programa de master em História, 2009, capítulo 3.

${ }^{19}$ Para a circulação e os suportes dos textos poéticos na Itália do Renascimento, ver BULLOCK, Walter Ll. Some notes on the circulation of lyric poems in sixteenth-century Italy. In: Essays and studies in honor of Carleton Brown. Nova Iorque e Londres: New York University Press e Oxford University Press, 1940, p. 220-41.

${ }^{20}$ GUARNERA, Elvira. Bernardo Accolti: saggio biografico-critico. Palermo: A. Giannitrapani, 1901, p. 127 e 128. 
peça? Acreditamos que a própria forma da composição da Virginia, isto é, sua métrica, a construção do espaço e do tempo da ação e outros elementos formais, traz traços bastante contundentes da encenação em si. Nesse sentido, o conceito de "ocasião formal", de Otto Pächt, parece-nos útil. Tratando da metodologia de estudo de imagens, ele afirma que a obra de arte pronta deve ser vista como uma tarefa que foi completada. Toda imagem seria, assim, produzida de acordo com a função a que ela se destina, de acordo com exigências da encomenda para um lugar específico em que a imagem seria coerente com seu lugar de visualização e uso. ${ }^{21}$ A mesma ideia parece-nos aplicar-se ao texto da Viginia. A própria construção do texto leva sem dúvida em conta o espaço da performance, os cenários e os movimentos dos atores.

Passemos agora ao texto da comédia, dividido em argumento, proêmio e cinco atos. A Virginia é quase inteiramente - os momentos de exceção serão importantes - escrita em oitava rima, isto é, em versos endecassilabi ${ }^{22}$ dispostos em estrofes de oito versos, cada uma com um esquema de rimas ABABABCC. O argumento (assunto, em português) que abre a comédia é um resumo da história que será representada. Trata-se de um soneto com esquema de rimas ABBA ABBA CDC DCD, isto é, composto de rimas interpoladas. O argumento é um momento anterior à peça, que a anuncia, mas não faz parte dela. Isso poderia explicar o emprego da forma do soneto no lugar da oitava rima que, como veremos, é dominante nas outras partes do texto.

O proêmio que se segue ao argumento emprega, no entanto, a oitava rima e, mesmo se não é ainda constitutivo da narrativa, faz a ela uma introdução formal. É aqui que se fala diretamente ao espectador, caracterizando-o - fala-se às mulheres, "belas e castas", e aos homens, "glória e honra do nosso Estado". Em seguida, anuncia-se a função do espetáculo que será apresentado:

${ }^{21}$ Para o conceito de “ocasião formal”, ver PÄCHT, Otto. Questions de méthode, op. cit,. p. 48-52.

${ }^{22}$ Em italiano, o número de sílabas de um verso é sempre estabelecido em relação aos versos piani, isto é, os versos em que a última sílaba tônica é a penúltima. Em um verso endecasillabo, a última sílaba tônica é a décima, mas há onze sílabas no total quando o verso é piano, daí o nome endecassilabo e não decassílabo, como na métrica portuguesa. BELTRAMI, Pietro G. La metrica italiana. Bolonha: Il Mulino, 1991, p. 22-25. 
E piatosi accidenti di costei

sol son representati a questo effetto

che ne casi sinistri, acerbi \& rei

mai si disperi uno spirto perfetto

$\&$ per mostrar che d'huomini \& di dei

Puo vincer l'ira un prudente intelletto

$\&$ ch'ardir, tempo, ingegno, oro \& parole

Fanno otenere al fin cio che l'huom vuole

(Os piedosos acidentes desta

São apresentados apenas com essa intenção

De que nos casos sinistros e acerbos e maus

Nunca se desespere um espírito perfeito

E para mostrar que de homens e deuses

Pode vencer a ira um intelecto prudente

E que ardidez, tempo, engenho, ouro e palavras

Fazem obter ao final aquilo que o homem deseja)

A função declarada do espetáculo é, portanto, como no caso dos painéis para spalliera, a instrução dos presentes - uma função moralizante -, a história de Virginia servindo para promover certo comportamento ou estilo de vida. Uma vez mais utilizamos a expressão "função declarada" posto que não se deve necessariamente tomar essa função como sendo válida ou, ao menos, a única função dessa peça. Entretanto, o fato de que se declare aos espectadores que a história a seguir traz uma lição de comportamento é essencial para a compreensão da construção do texto e, evidentemente, de sua recepção.

Após o proêmio, apresenta-se uma sequência de cinco atos. Esse número de atos não é escolhido ao acaso, mas segue as edições humanistas de peças clássicas de Plauto que, respeitando os preceitos de Horácio, adotaram essa divisão apesar de ela não figurar nos manuscritos a partir dos quais foram preparadas. ${ }^{23} \mathrm{~A}$ extensão desta peça teatral impede-nos, no espaço de que dispomos, de acompanhá-la cena a cena, ato a ato. Optaremos, pois, por analisar unicamente o primeiro ato, ressaltando, em algumas passagens, elementos estruturantes da narrativa que julgamos fundamentais à construção de uma percepção do espaço e do tempo por parte dos espectadores.

${ }^{23}$ STÄUBLE, Antonio. La comedia umanistica del Quattrocento. Florença: Istituto Nazionali di Studi Sul Rinascimento, 1968, p. 155. 
O primeiro ato começa com um monólogo da personagem-título, na qual ela exprime todo o seu sofrimento de amor pelo príncipe de Salerno. Este é interrompido pela chegada do mensageiro da corte, de quem ela receberá a notícia de que o rei está muito doente e de que nenhum médico conseguira até aquele momento curá-lo. Virginia, filha do médico Hipócrates, lembra-se de que seu pai já havia curado uma rainha da mesma doença que afligia então o rei. Ela decide, pois, em posse do medicamento miraculoso, ir ao encontro do monarca para tentar, como recompensa por ter restabelecido a sua saúde, receber o príncipe de Salerno como marido. Uma vez na presença do rei e diante de sua incredulidade, Virginia aceita um acordo: se ele estiver curado em oito dias, ela receberá um nobre da corte em casamento, mas, se ele ainda estiver sofrendo depois de esse tempo ter passado, ela morrerá na fogueira.

Feito esse acordo, apresenta-se claramente o problema da passagem do tempo na peça - é preciso esperar oito dias para conhecer o destino de Virginia. O modelo clássico, em grande medida adotado pela tradição humanista no Renascimento italiano, não permitia narrativas que se estendessem por longo período de tempo. ${ }^{24}$ Trata-se de um princípio proposto por Aristóteles na Poética, de acordo com o qual o teatro deveria sempre respeitar três unidades: tempo, espaço e ação. O tempo da história narrada não deveria estender-se por vários dias, o espaço não deveria mudar e apenas as cenas que fazem avançar de fato a narrativa seriam bem-vindas. ${ }^{25}$

A unidade de ação, a mais importante segundo Aristóteles, não é tampouco respeitada por Accolti. Uma vez que Virginia aceita o acordo com o rei, as personagens principais desaparecem de cena e nos vemos, então, na presença de dois servos da corte, Iulio e Sylvio. O diálogo entre eles servirá para preencher o tempo de espera que a narrativa impõe e caberá a eles nos conduzir do ponto inicial até o momento de revelação da sorte de Virginia. Trata-se, na verdade, do que chamaremos de "figuras de transição narrativa". Eles não possuem nenhum papel ativo no desenvolvimento da ação, mas têm por função conduzir o espectador através do tempo e do espaço até a retomada da narrativa.

Há, de certa maneira, um rompimento articulado dos princípios aristotélicos de unidade de tempo e ação, em que uma ação desnecessária para o desenvolvimento narrativo serve para fundar a passagem de um longo período de tempo na

\footnotetext{
${ }^{24}$ Idem, ibidem, p. 154.

${ }^{25}$ ARISTOTE. Poétique. Paris: Les Belles Lettres, 2002. Para uma interpretação desses preceitos da Poética no Renascimento italiano, ver ANDREWS, Lew. Story and space in Renaissance art: the rebirth of continuous narrative. Cambridge e Melbourne: Cambridge University Press, 1995, p. 22 e 23.
} 
percepção dos espectadores. O diálogo entre os dois personagens secundários e um longo monólogo lamentando o possível destino trágico de Virginia criam, materialmente, a passagem do tempo. Somos confrontados, de início, com uma lamentação de Iulio, em quatro estrofes - o comprimento sendo importante para criar uma impressão de passagem do tempo. Em seguida, Sylvio chega e tenta acalmar seu colega que, nesse momento, manifesta intenção de suicidar-se para não ter de testemunhar a morte de Virginia. Sylvio lhe diz, então, que não deve se desesperar, porque Virginia conseguiu curar o rei e está, portanto, salva de um destino cruel. Por fim, diante da incredulidade de Iulio, Sylvio o convida a seguilo para ver com os próprios olhos o que se passa. É evidente que, com Iulio, os espectadores são também convidados a reencontrar os personagens principais, a continuação das ações e do desenvolvimento da narrativa.

Na sequência, Virginia pede, então, para a surpresa do monarca, a mão do príncipe de Salerno em casamento. Após certa hesitação, o rei acata o pedido de sua salvadora e vai ao príncipe comunicar-lhe de sua decisão. O diálogo entre o rei e o príncipe será o primeiro conflito verbal da peça:

Arme non sposa vuo seguire. Re. La sposa

Non impedisce armarti \& stare in sella

Non è di regal sangue. Re. È virtuosa.

Nobil non è. Re. Ell'è casta \& è bella

Mia casa infamo. Re. Tanto è gloriosa

Que non bisogna aggiunger gloria a quella

Dota non ha. Re. Da me la dota harai

Mai non consento. Re. Si consentirai
Princ.

Princ.

Princ.

Princ.

Princ.

Princ.

Esse primeiro conflito verbal do texto é também a primeira aparição de "versos quebrados", isto é, versos divididos entre duas personagens ou mais. Parece-nos claro que a divisão do verso é um mecanismo de produção de tensão no interior dos diálogos. Vemos aqui a importância da métrica para a recepção: todos os versos são endecassilabi, e a constância dessa medida faz com que esperemos sempre que o verso se complete nessa unidade sonora. $\mathrm{O}$ fato de que a reação de um personagem esteja no mesmo verso da fala à qual ele reage reforça a ideia de reação dura e urgente, uma vez que contida na mesma unidade mínima - o verso. É como se a reação fosse tão obrigatória para a narrativa quanto a continuidade do verso é para a conclusão sonora do verso. A interrupção dos versos quebrados marca o fim do conflito quando o príncipe, conformado, diz: "Sou teu servo e podes obrigar-me, ó rei / Mas não serei nunca mais feliz." 
Os versos quebrados serão empregados em vários momentos de conflito ao longo da peça, seja para criar um efeito de tensão, seja para dar efeito cômico, como no caso dos diálogos do príncipe com seu empregado Ruffo, no segundo ato. Tanto o drama como o humor beneficiam-se dessa aceleração do ritmo que retém a atenção do espectador.

O príncipe tendo aceitado o seu destino, o casamento ocorrerá na sequência. Imediatamente após, o ato é encerrado com uma estrofe de três versos endecassilibi e rima ABA. É a primeira vez que a oitava rima será interrompida, o que, parece-nos, cria um efeito de suspensão que joga uma vez mais com as expectativas do público. Espera-se por uma continuidade da estrofe, mas ela não virá.

Hor andian drento alla famosa cena

Sia in questa note fatto festa $\&$ gioco

Che veramente è felice \& serena.

Poderíamos supor que essa suspensão da oitava rima é mais um artifício de passagem do tempo, a unidade da estrofe que era esperada sendo completada no tempo da celebração que se anuncia, mas que não será vista em cena.

\section{Virginia e Griselda: objetos, espectadores e convenção}

A comparação entre os mecanismos narrativo-visuais dos painéis da história de Griselda e aqueles da história de Virginia permite-nos inferir uma parte das condições nas quais, nas relações sociais estabelecidas em Siena no final do século $\mathrm{XV}$, o encontro entre objeto e espectadores produziu sentido. A comparação dos mecanismos de duas mídias diferentes torna possível destacar os mecanismos que comandavam, nesse momento, a apresentação desses objetos ao público. As mesmas pessoas que assistiram à Virginia colocaram-se diante dos painéis da paciente Griselda. Com isso, certamente, a experiência de recepção do espetáculo terá contribuído para a condução do olhar do espectador sobre os painéis assim como o conhecimento do funcionamento narrativo dos painéis terá influenciado a percepção que se teve do espetáculo teatral. Obviamente, não se trata aqui apenas destes objetos especificamente, mas de todos os painéis de casamento conhecidos à época e dessa tradição teatral a que esse público está acostumado.

$\mathrm{Na}$ literatura mais tradicional da história da arte, o Renascimento italiano é um momento de aproximação da pintura com o real, em que toda imagem torna-se, consequentemente, representação, isto é, uma cópia do real. Essa noção apresenta o grave problema de remeter a uma exterioridade a vida da imagem, que deixa de ser ela mesma para tornar-se a retomada de algo que lhe é externo. Isso vai, 
evidentemente, na direção oposta ao que se propõe aqui, isto é, compreender a imagem como elemento ativo da sociedade de que ela faz parte.

A forma mesma do espetáculo, sua métrica, os lugares comuns do gênero e outros, tudo isso comunica uma convenção que deve ser entendida e respeitada, e é isso - e não a promoção da verossimilhança que, em geral, se atribui ao Renascimento - que tem um papel fundamental na organização das relações entre espetáculo e público. Da mesma maneira, das pequenas figuras da história de Griselda não se esperará que elas respeitem a verossimilhança, que seus corpos estejam de acordo com as proporções de corpos humanos ou que o espaço seja ocupado de maneira a respeitar as leis da física. Esses corpos são também dispostos de acordo com esses mesmos lugares comuns, as mesmas regras de organização que nos permitem compreender a história que é narrada. É somente porque compreendemos como a história é contada (sua forma) - e este é o caso dos Spannocchi e de seus convidados - que somos capazes de compreender o que nos é contado, ou seja, o conteúdo da narrativa.

Nos painéis pintados, vimos que as figuras com corpos disformes ou torcidos conduziam-nos a imaginar a conclusão de movimentos. Diante de uma cabeça virada fortemente para a direita, por exemplo, imaginamos que o corpo deverá acompanhar esse direcionamento para que o movimento esteja completo. Esses movimentos são percebidos como sendo necessários ou obrigatórios de acordo com as convenções que estão na base dessa tensão. Joga-se com a forma e com as convenções, e é a convenção, e não o real, que informa o espectador de como deve ser a imagem de uma figura humana. Toda deformação dessa forma esperada produz uma tensão, um desejo de atingir a forma convencional, a forma conhecida, na qual poderemos relaxar tendo atingido nossa expectativa. Da mesma maneira, na Virginia, toda frustração de expectativa produz tensão e conduz-nos a buscar a conclusão de movimentos que são percebidos como obrigatórios para que se mantenham as regras gerais de funcionamento do conjunto. Se o que esperamos é uma estrofe em ottava rima, mas encontramos uma terzina, torna-se necessário, de alguma maneira, preencher essa falta. No caso do primeiro ato, essa falta constrói o tempo da festa que se anuncia para a sequência, mas que não será encenada. Nos dois casos, nos painéis e na peça, é porque os autores partilham um mesmo código com o público, que o respeito a esse código ou a sua perversão são eficazes.

Tanto os painéis quanto a Virginia possuem mecanismos de forjamento do espaço-tempo com participação ativa dos espectadores. Nos painéis, os espectadores são responsáveis pela própria ordem da narrativa, enquanto na Virginia estabelecem a correlação entre o tempo da performance e o tempo dos eventos 
contados. Na série da Griselda, a passagem do tempo se dá a partir de uma multiplicidade de mecanismos plásticos, numerosos em cada um dos painéis, mas variáveis de um painel a outro. Poderíamos mencionar, por exemplo, a progressão da esquerda para a direita, a passagem dos planos mais recuados para os planos mais próximos, as tensões de movimento que remetem o espectador em direção a uma cena adjacente e as formas circulares que não nos permitem a permanência do olhar sobre uma única figura. $\mathrm{O}$ fato mesmo de que haja tantas formas de organização da narrativa no tempo cria uma multiplicidade de temporalidades que não se organizam a não ser sob o olhar de alguém que busque dar-lhes uma ordem.

Os mecanismos de tempo na Virginia visam, sobretudo, indicar a passagem do tempo durante a ausência de ações visíveis em cena. A imaterialidade do tempo também ganha concretude por meio da voz de um personagem que, em seu monólogo, anuncia que um ano se passou. Tanto aí como nos painéis, o tempo não existe a não ser que seja instaurado na percepção dos espectadores, seja durante o ato de observação da pintura, seja quando durante a performance da peça teatral.

Se o movimento, como já se afirmou anteriormente, é fundamental para a instauração do tempo, é evidente que dele também depende a criação do espaço. O espaço contínuo dos painéis encontra paralelo no espaço da performance da Virginia, em que, muito provavelmente, a separação entre os diferentes espaços nos quais se desenvolvem as ações depende fortemente de indicações textuais, o que nos mostra que o cenário era mínimo ou pouco específico. Cabe, portanto, ao espectador, para além das informações visuais, fazer a separação dos espaços e localizar assim cada uma das cenas. Aqueles que veem os painéis devem compreender que a casa dos pais de Griselda não é ao lado do palácio do marquês e que o cortejo, no terceiro painel, não está passando logo atrás das arcadas sob as quais se dá o banquete. Da mesma maneira, na Virginia, são os personagens que nos contam onde estamos, na casa de quem, se estamos em área interna ou externa. Cabe a nós organizar os espaços e compreender como a narrativa, o espaço e o movimento articulam-se a cada momento.

Tanto para a constituição do espaço e do tempo como para conectar as ações que fazem avançar a narrativa na Virginia e nos painéis da Griselda, emprega-se aquilo que chamamos aqui "figuras de transição narrativa". Essas figuras humanas, que preenchem espaços entre cenas nos painéis e são personagens sem ação transformadora da narrativa, servem para conduzir o espectador em direção a outro lugar seja no espaço, seja no tempo. A presença dessas figuras é, de fato, o melhor exemplo dos limites da ideia de representação, posto que elas não se limitam a re-presentar ou re-tomar uma existência que lhes é externa. Antes de serem figuras humanas, esses "personagens" são prioritariamente formas, isto 
é, elementos formais que atuam na organização da narrativa. Eles possuem, por exemplo, a mesma função da pontuação nas línguas modernas ou da métrica e da divisão em estrofes no texto poético. Dizer que essas figuras são representações de figuras humanas é ignorar sua existência formal no interior seja dos painéis da história de Griselda seja na Virginia.

O que esperamos ter mostrado com a análise dos painéis e da Virginia e com esta breve comparação entre os dois é que os objetos, ao mesmo tempo que se inserem em uma lógica mais geral determinada pelas convenções de gênero, não ganham sentido a não ser no ato da recepção por um certo público. $\mathrm{O}$ sentido não está, portanto, contido no objeto; ele se encontra na dialética entre objeto e espectador. A recepção que se tinha desses objetos dependia, consequentemente, de um evento, do encontro entre objeto e espectador em um dado momento.

Recebido: 20/05/2011 - Aprovado: 05/08/2011. 